\title{
The Effectiveness of CATA Software in Exploring the Significance of Modal Verbs in Large Data Texts
}

\author{
Ayman F. Khafaga \\ College of Science \& Humanities, Prince Sattam bin Abdulaziz University, Saudi Arabia \\ Faculty of Arts \&Humanities, Suez Canal University, Egypt
}

\begin{abstract}
This paper investigates the effectiveness of using and applying CATA (Computer-Aided Text Analysis) software in exploring the extent to which particular modals are significant in communicating the ideological and thematic messages of literary discourse. More specifically, the paper attempts to test the hypothesis that CATA software, including FDA (Frequency Distribution Analysis), KWICK (Key Word in Context), CA (Content Analysis), and TDA (Thematic Distribution Analysis) are effectively helpful in the linguistic and ideological analysis of modals in literary texts. To this end, the paper uses the frequency distribution analysis (FDA) and applies it to Edward Bond's Lear as a sample representing literary texts. Two modal verbs were selected to be computationally analyzed by means of the frequency distribution analysis in order to decode the different ideologies they carry in the discourse of the selected play. These are will and must. These modal verbs were computationally displayed within their contextual, total and indicative occurrences in the play under investigation to demonstrate the way they convey particular ideologies. Findings revealed that CATA software represented in its variable of FDA is highly contributive to communicating ideologies in the play under investigation. The paper further demonstrated two findings: first, via CATA software, analysts can easily arrive at the ideological significance of the various classes of words, including modal verbs that are used in literary texts; and, second, the analysis showed that only a few occurrences out of the total number of frequencies of the modal verbs at hand are indicative in conveying the hidden ideologies of their users.
\end{abstract}

Keywords-CATA software; frequency distribution analysis; ideologies; modal verbs; Bond's Lear

\section{INTRODUCTION}

It is perspicuously evident that the application of computer software contributes significantly to the linguistic and stylistic study of literary and fictional texts, particularly to decode the different themes and ideologies pertaining to this type of texts [1], [2] and [3]. These computational software offer analysts and researchers the ability to arrive at authentic, reliable, and credible results in an accurate and precise way more than any other analytical tools that would be conducted without the interference of computer [4]. The current study scrutinizes to reveal the various ideologies pertinent to the usage of the modal verbs in one of the literary texts represented in Edward Bond's Lear. Beyond the choice of the play under consideration, the rationale lies in the fact that the majority of fictional texts, particularly the literary one abound in huge number of modal verbs that are usually utilized for particular grammatical purposes, including the expression of obligation, possibility, desirability, certitude, etc. [5]. This paper, therefore, offers a linguistic investigation of the importance of modal verbs in the play at hand by using two analytical dimensions. First, by using and applying the frequency distribution analysis (FDA), which will be activated by the program of concordance in order to display the different occurrences pertaining to each modal verb under investigation (i.e., will and must). Second, to reveal the ideological importance these modal verbs are employed to communicate in Edward Bond's Lear. Crucially, the current article scrutinizes to test the hypothesis that the incorporation of the latest developments of applying technology into the textual and contextual analysis of texts contributes significantly to the general understanding of texts, specifically, large data texts manifested in the context of this paper in the conversational literary genre.

In fact, with the unrelenting development of technology, computer software has become increasingly important in various types of corpus linguistics studies, where it is used to extract both theoretical and empirical conclusions toward textual analysis in general and to the field of linguistics specifically [6], [7], [8], and [9]. The findings of these studies indicated that computer software provides essential support and facilitation for a wide-ranging and improved analytical environment, in which analysts and stylisticians are able to conduct analysis in an efficient and effective way. This is conducted by providing ample, credible, and adequate results. Incorporating computational techniques in corpus linguistics studies not only facilitates the entire text analysis process, but also highlights the inclusion of technology as well as other social and human sciences into the research pertinent to corpus linguistics, stylistics, pragmatics and the various scopes of discourse studies [10].

In terms of its theoretical framework, the paper is grounded on two analytical frameworks: the first constitutes Fairclough's [11] approach to critical discourse analysis, in which he investigates various grammatical concepts relevant to the study of ideology in discourse, either written discourse or spoken discourse. Fairclough's perspective to the analysis of the grammatical concepts focuses, among other concepts, on the use of modal verbs as conduits of particular ideological and discursive purposes. The second dimension to be used here is a computer-aided text analysis (CATA); this digital tool will analytically be enabled, as alluded before, by a frequency distribution analysis (FDA), through which the two modal verbs at hand will undergo a digital analysis that serves to arrive at the frequencies of each modal verb in text as well as its contextual environment in discourse. Significantly, core 
concern beyond using both CDA and FDA in the analysis of Bond's Lear [12] ultimately functions to explore the ideologies conveyed by the modal verbs at hand, and to highlight analytically the integration of modern technology and critical discourse studies. This is conducted by demonstrating the significant part modal verbs have in communicating various ideologies in discourse through showing the significant and insignificant occurrences of the modals under investigation.

The application of CATA via the frequency distribution analysis to linguistically investigate modal verbs as conduits of ideology in discourse mirrors the extent to which modal verbs in general and the modals under investigation in particular have linguistic and ideological weight in communicating meanings among conversationalists, either at the fictional level of discourse, as is the case in the current study, or in reality, that is, in everyday occurring conversations [13]. Crucially, large data texts are a fertile field in which computer software can be applied to uncover the hidden meanings and ideologies encoded in these texts [14-15]. The assumption that discourse is ideologically-loaded makes us proclaim that any type of discourse carry some sort of ideological importance. That is, any text is supposed to have an ideological message. These ideological messages can be decoded by means of various analytical tools. Among these tools are CDA and CATA, which are adopted in the analysis of this article [16]. Regardless of the fact that communication in literary texts is totally fictional, it remains a fact that these fictional communications reflect what is happening in the real world [17]. This, of course, shows the reason why Lear as a representative of large data texts is selected for the analysis in the current article.

\section{A. Research Questions}

Three research questions are attempted to be answered in this article as follows:

1) How does an FDA contribute to the analysis of modal verbs in fictional texts?

2) What are the various ideologies conveyed by the modal verbs in Bond's Lear?

3) To what extent does Key Word in Context (KEWIC) variable contribute to the intelligibility of the weight of specific modal verbs within particular contexts in literary discourse?

\section{B. Research Objectives}

Three research objectives are attempted to be achieved in this paper. These are as follows:

1) To show the way CATA contributes to the studies of ideologies in discourse, particularly in relation to the modal verbs investigated in the current article.

2) To highlight the harmonizing connection between CDA and CATA.

3) To explore the different ideologies modal verbs communicate in the play under investigation.

In the remaining part of this article, the paper will present the theoretical preliminaries and the literature review in
Section II. The study also provides the method adopted in its analytical part, as well as the analytical procedures in Section III. In Section IV, the paper offers the analysis of the selected data. The discussion of the obtained results will be the focus of Section V, whereas the Section VI is dedicated to the conclusion and recommends some ideas for further research.

\section{LITERATURE REVIEW}

\section{A. Computer-Aided Text Analysis}

According to [18], the use of computational software in the textual and contextual analysis of texts is highly contributive to deciphering the hidden ideologies and the various propositional meanings pertaining to these texts. He also emphasizes that these software can be employed within the framework of computer assisted language learning (CALL) to facilitate the process of learning and teaching. It is also obvious that computer software contribute significantly to the linguistic and stylistic investigation of large data texts, particularly the fictional and literary ones. Such computational application of various programs and software makes it easy for linguists and discourse analysts to arrive at specific ideologies and meanings at the various levels of the linguistic analysis; that is, the level of the word, the level of the phrase, the level of the sentence, and the level of the utterance. This, in turn, accentuates the importance of the work of computer in the analysis of the different discourse genres, as it helps arrive at concise and credible results that are supposed to be thorny if the linguistic investigation is conducted manually, that is, without the computational work [19]. Such contributive role of computational analysis is not only manifested in the studies within the scope of linguistics, but it also exceeds this analytical focus to cover other fields, either in linguistics or in other social disciplines. Thus, computer software can be applied to studies in the fields, such as pragmatics, semantics, stylistics, etc [20]. This computational perspective towards the analysis of the various types of texts ends any case in which the reliability, authenticity and credibility of analysis that is conducted without computer. This is because computer serves to arrive at very authentic and concise results for any text [21].

Importantly, computer-assisted text analysis provides a wide range of analytical methods and possibilities that are valuable in the stylistic, semantic and pragmatic investigation of gigantic data texts, particularly fictional writings. The Frequency Distribution Analysis (FDA) is one of these analytical options, and it solely allows you to see how many times a searched item appears in a text. According to [22], frequency analysis allows analysts to acquire a rough notion of the textual nature of specific lexis in a text. This also aids in steering the analytical wheel toward a significant precedence of one occurrence over another, which is made possible by CATA's second variable, the Key Word in Context variable, which is computationally enabled (KWIC). The context in which a searched phrase appears is indicated by the KWIC variable. To put it another way, KWIC explains the context of the searched items, which aids in determining the ideological value of words and/or sentences [23]. Content Analysis is another analytical option provided by CATA (CA). For [24], content analysis is used to divide words into classes based on their semantic characteristics. Researchers and text analysts 
use content analysis in conjunction with other CATA factors to determine the thematic and ideological relevance of certain words in texts.

In the context of this article, CATA is enabled to give the analytical alternatives indicated above by the Concordance program. Concordance is a computer application that allows analysts and users to collect, access, classify, and analyze various sorts of texts, especially those that contain enormous amounts of data [25-26]. Concordance can thereby retrieve all instances of a searched lexis in a text, display the contextual context of any word, and categorize all words based on their semantic meaning [27]. The ideologies represented by the modal verbs in the selected data will be revealed by deriving the frequency distribution of the modal verbs under consideration, which will be supplemented by both the use of KWIC and content analysis to reveal the ideologies represented by the modal verbs at hand.

\section{B. Critical Discourse Analysis}

Fairclough [11] presents four sets of items for the linguistic study of function words in texts and speech, based on his research into the role of modal verbs and their ideological relevance in discourse studies. The first set demands a study of textual experiential values, which necessitates a modality analysis. The second group focuses on the grammatical elements of texts, such as the style of phrase used (declarative, interrogative, or imperative); the type of modality utilized (truth, obligation, or possibility modality); and the type of pronouns used in discourse. The final group of items focuses on the expressive value of grammatical features like expressive modality. The fourth set examines the many sorts of sentences employed, such as simple, compound, and complicated, as well as the relationships between the various sentence forms. Fairclough's collections of items are rich in grammatical features that contribute to the production of ideologically charged discourse. Specifically, in terms of studies that pertinent to stylistics, ideology, pragmatics, discourse studies, and power relations [28], [29], and [30], modality is used discursively to express, develop, and retain agency. The reason for this, according to these studies, is that agency is inextricably linked to conceptions of power and dominance, and it is intricate to find any type of ideological discourse that does not present as its core concern notions and themes of power, control, persuasion, and manipulation. Modal verbs, in particular, can function as ideology carriers in language under certain settings.

\section{Modal Verbs}

These modal verbs are categorized into relational and expressive modality based on Fairclough's premise about modal verbs [11]. According to him, such cataloging is founded on the speaker's authority over his or her addressees. The focus in relational modality is on both the authority and discourse access of the speaker in relation to the various semantic propositions communicated by language. In expressive modality, on the other hand, the focus is on the authority of the speaker with regard to the degree of truthfulness concerning the content of discourses. Modality, he claims, can be articulated linguistically not only through modal verbs, but also via other devices of grammar, such as adverbs and tense. According to Fowler [31], there are four sorts of modality: truth, obligation, permission, and desirability. Modal auxiliaries like 'will' and adverbs of certitude like 'surely' can be used to communicate truth modality. This modality demonstrates that the speaker's assumption is correct. To communicate a high level of certainty, truth modals are utilized. Some modal auxiliaries, such as 'must, 'should,' or 'ought to,' can be used to create an obligation modality. The obligation mode focuses on the perceptual attitudes of discourse participants towards the implementation of the semantic proposition pertinent to the speaker. The modal auxiliaries, such as 'can,' present the permission modality, which is employed to provide discourse participants the ability to communicate the language function of permission. The speaker's status of accepting or denying what is expressed by his/her offer is clarified by the desirability modality. In light of this paper, only two types of modal verbs will be discussed: truth modality (will) and obligation modality (must).

\section{Related Studies}

When looking at prior research on the usage and deployment of computer software in general, and frequency distribution analysis in particular, it is clear that these programs are quite useful for analyzing massive data sets like fictional novels. [32], for example, looked into the semantics, rhythm, and tempo of narrative storytelling using data mining. They determined how much input data might influence the final perception of fictitious literature and concluded that the process of data mining, which is conducted through visualization, can in turn mimic the semantic classification and thematic clustering carried by fictional texts.

Another study conducted by [33] looked into the effectiveness of concordance in the analysis of fictitious discourse. This research showed that concordance may be applied to massive data texts to produce legitimate and believable results that help with text comprehension. Both the FDA and the KWIC were the two analytical variables presented in this study, which were generated using concordance. The study indicated that utilizing and applying concordance to the investigation of literary texts aids in achieving a high level of intelligibility at the level of representation of various themes and ideologies, as well as determining the writer's intended meaning.

A further study presented by [34], in which they demonstrated the importance of using new technological software in developing reliable translation versions in the field of translation studies. The study advised using computer software into the teaching and learning of university translation courses in Saudi Arabia's various academic institutions. Furthermore, [35] conducted a study on the impact of CALL software on the academic competence and performance of Saudi university students, who are studying English as a foreign language. The use of CALL to EFL settings has a good impact on EFL students' learning results, according to this study. The main objective of this study is to see how effective the two computer apps SnagitTM and Screencast are at helping people learn to read. The study found that using the two computer software programs helps pupils enhance their academic performance by cultivating 
language abilities that are important for learning to read. The study also found that incorporating technology into EFL classes helps students strengthen not only their linguistic skills, but also their communicative abilities. The study concluded by proposing the use of CALL software in the context of Saudi universities and in the course designation process at Saudi institutions for various EFL courses.

Within the scope of legal studies, [36] investigated the extent to which concordance helps analyze the linguistics of the opening statements by revealing the numerous pragmatic meanings and concealed ideologies that lies beyond the mere semantic propositions that are expressed at the surface level of the semantics of texts. The study further accentuates the effective role computational analysis provides to uncover the mystifying meanings and the pragmatic purposes attempted to be clarified on the part of writers and/or speakers. Significantly, this study states that these ideological activities within textual and contextual analyses can be revealed and conducted via the repeated usage of particular lexical elements in the investigated texts. The research stated above demonstrate the usefulness and contribution of computer software in linguistic studies, whether on fictional texts or outside the realm of fiction, such as in EFL and courtroom contexts. The usage of CATA to discover further and new meanings in texts, particularly those that are produced by function words in large data and fictional texts is expected to be expanded in this study so as to offer fertile insights into the contributive way CATA software are employed to explore the various meanings pertaining to this type of texts.

\section{METHODOLOGY}

\section{A. Data Collection and Description}

Edward Bond's Lear is included in this study's corpus. The play is divided into four acts, each of which contains eighteen scenes that make up the entire production of the dramatic piece. The reason for choosing this play in particular is that it contains a substantial amount of grammatical elements that are useful in transmitting various views, ranging from persuasive to manipulative. This is demonstrated by the frequency analysis included in this article, which demonstrates an ideological weight for such grammatical characteristics; they are not used haphazardly in the play's dramatic dialogue, but rather serve as ideological containers. Bond's Lear, in particular, has distinctive discourse features that allow an investigation of the ideologies encoded in the play at hand, particularly in terms of the deft use of modality to transmit beliefs and communicate ideological meanings.

As for the play itself, it is a rewriting of Shakespearean masterpiece King Lear. The play narrates the story of a king who has two daughters and, like Shakespearean king, he decides to surrender his kingdom to them. The two daughters betray their old father, dismiss him outside their homes, and cause him to madness. The play shows the extent to which political ideologies are communicated in discourse. It also sheds light on the way language is employed not only to persuade, but also to manipulate. In light of the current article, it will analytically be shown how modal verbs are utilized to convey such persuasive and/or manipulative ideologies. This, as mentioned before, will be conducted by the application of CATA software manifested in an FDA.

\section{B. Analytical Procedures}

The analytical procedures adopted in this study constitute three stages. Three CATA variables were used in each stage: frequency distribution analysis (FDA), key word in context (KWIC), and content analysis (CA). The first step was to prepare the text of the chosen play by electronically uploading it so that it could be analyzed. This stage gave an overview of how the play's discursive tone is conveyed through the characters' conversational turns. The modal verbs (will and must) were electronically illuminated in the second stage to mark their appearance in the play. This was accomplished by applying an FDA to the entire text of the play at hand, and tracking the various occurrences of each searched token. The final stage consisted of an interpretive exercise in which all of the highlighted elements were investigated in terms of their likely occurrences in the context in which they occur. Findings were first presented and then analyzed in terms of the amount to which the searched items contributed to transmitting specific persuasive and/or manipulative ideas following the three stages of analysis.

\section{The Frequency Distribution Analysis}

The work of concordance was limited to the analytical process, by providing an FDA for the searched lexical elements that were identified as significant in the study of modality as ideology indicators. Concordance is used to conduct this frequency analysis. Concordance makes it easier to access and examine big data texts in order to produce reliable and succinct results that would be impossible to achieve if the analysis were done without the aid of computer tools [37-39]. In this case, the concordance options simply allowed you to mark the word in its context. This serves as a quick summary of the linguistic context in which the term appeared in the text. Concordance, according to Kennedy [20], is software that generates all instances of a given word or lexis in a corpus. Furthermore, according to Hockey [19], a concordance or frequency analysis is formed by the searched item and the context in which it occurs. For example, Concordance provides KWIC (Key Word in Context), which provides a wealth of information about the searched word in its many contexts in text. As a result, the interpretative process is extended, opening up new perspectives that aid in better understanding the language representation.

\section{DATA ANALYSIS AND RESUlTS}

This section presents an FDA of the modal verbs under investigation. The modal verbs will analytically be divided according to their semantic functionality into three categorizations: first, the modal verbs that indicate truthfulness and certitude (will); and, second, the modal verbs that communicate obligation (must). This will be accompanied by a content analysis and a key word in context analysis to clarify the ideologies carried by these modal verbs in the play under investigation.

\section{A. An FDA of the Truth Modals}

The truth modal 'will' is employed by many characters in the discourse of the play to emphasize their credibility and 
demonstrate the veracity of their words The modal 'will' is utilized in Lear to convey both persuasive and manipulative ideologies. In more than one situation in the discourse of Lear, both Fontanelle and Bodice tried to convince their father, the old king, to permit and approve their furtive marriage from his ancestral foes, the duke of North and the duke of Cornwall, as mentioned in the preceding extract. They both know their father would reject their marriage, so they utilize the truth modal 'will' to sway their father's attitude toward their husbands. Fontanelle's statement, "I know you'll get along with my husband," expresses her desire to marry Cornwall. Bodice's remark that she'll soon learn to respect them as if they were her sons is yet another attempt to persuade her father to approve her marriage from the North. Bodice's usage of the pronoun 'you' demonstrates her authority in communicating with her father. The two daughters attempt to eliminate Lear's fear of the two husbands from his thoughts so that he will accept their marriage without reservation. A frequency distribution analysis of the manipulative and persuasive 'will' is presented in Tables I and II.

TABLE I. A FREQUENCY Distribution ANALYSIS OF MANIPULATIVE 'WILL'

\begin{tabular}{|l|l|l|}
\hline The Modal Verb & Total Frequency & Indicative Occurrences \\
\hline Will & 77 & 5 \\
\hline
\end{tabular}

TABLE II. A FREQUENCY DISTRIBUTION ANALYSIS OF PERSUASIVE 'WILL'

\begin{tabular}{|l|l|l|}
\hline The Modal Verb & Total Frequency & Indicative Occurrences \\
\hline will & 77 & 4 \\
\hline
\end{tabular}

Tables I and II demonstrate that the truth modal 'will' has a total frequency of 77 occurrences; only 9 occurrences are significant in conveying specific meanings and ideologies, 5 of which are utilized to convey manipulative ideology (Table I), and 4 occurrences are employed to channel persuasive ideology (Table II). The complementary link between the two CATA variables employed here, the FDA and the KWIC variables, is further highlighted in these two tables. To further elucidate this point, it is clear that, despite its ability to provide us with the total frequency of a certain word, FDA is still unable to assist us in better understanding the indicative occurrence of that term. Only by using the KWIC variable can one determine what is suggestive and what is not among occurrences. The two factors' complimentary nature discursively supports the entire interpretative atmosphere of the play under investigation.

\section{B. An FDA of the Obligation Modals}

It is grammatically known that the modal 'must' is recurrently used to communicate the grammatical function of obligation. This obligation modal is deftly deployed in Bond's Lear to depict the speaker's authority over his audience. Obligation modals are used by speakers to impose their own ideology on their listeners and to drive their conduct toward perfect compliance and subordination to their goals [40]. The employment of the obligation modality dominates oppression discourse, in which powerful characters use these modals to exercise dominance over the powerless.
Bodice and her sister, Fontanelle, are discussing their plot to attack Lear's army and evict him from his throne. Bodice use the obligation modal 'must' three times to highlight the importance of accomplishing what they plan to do, as well as the urgency of attacking their father in order to stop the acts of building on the wall. We must travel to our spouse, we must attack before the wall is done, and we must aid each other are all obligation modals used by Bodice to highlight her authority and dominance over her sister. Even in her relationship with her spouse, she directs her. The pronoun 'we,' which accompanies the modals, reflects unity, which Bodice tries to convey to Fontanelle in order to ensure that she is looking out for her sister's best interests; this, in turn, pushes Fontanelle to willingly carry out what her sister demands. As a result, the obligation modal 'must' is perverted in order to channel deceitful ideology. The frequency analysis that follows provides greater insight into the manipulative use of the obligation modal 'must' in both affirmative and negative variants.

TABLE III. A FREQUENCY DistribUtion ANALYSIS OF 'MUST'

\begin{tabular}{|l|l|l|}
\hline The Modal Verb & Total Frequency & Indicative Occurrences \\
\hline must & 100 & 13 \\
\hline
\end{tabular}

TABLE IV. A FREQUENCY DisTRIBUTION ANALYSIS OF 'MUSTN'T'

\begin{tabular}{|l|l|l|}
\hline The Modal Verb & Total Frequency & Indicative Occurrences \\
\hline Mustn't & 9 & 1 \\
\hline
\end{tabular}

Tables III and IV show that in the novel's discourse, 13 occurrences of the affirmative 'must' and 1 occurrence of the negative 'mustn't' are used as bearers of manipulative ideology. The negative obligation modal, although its rarity, is very indicative in transmitting manipulative views. The fact that a term appears frequently does not necessarily mean that it is thematically suggestive. Low frequency terms, on the other hand, are often quite suggestive.

\section{DISCUSSION}

The analysis demonstrates that the modal verbs of truth (will) and obligation (must, mustn't) Go beyond their grammatical and semantic duties to express and sustain certain pragmatic and ideological meanings, such as persuasion and manipulation, at times and in specific settings. In the discourse of Bond's Lear, the modal verbs under consideration express a distinct form of ideology. Truth and obligation modalities are particularly important in expressing both persuasive and manipulative ideas in the play's discourse, according to analytical data.

The analysis demonstrated that the use of CATA software aids in the extraction of new meanings and ideologies that are supposed to be unclear to the ordinary reader. This computational approach to textual analysis further serves to achieve better understanding of the significant role of modal verbs as conduits of particular meanings. It also functions to enhance the discursively analytical amalgamation of discourse studies and computers, especially in the linguistic analysis of massive data texts. The two variables FDA and KWIC are harmonizing in nature, because the latter is a context-oriented 
variable that focuses on the recognition of significant words created by the former's total occurrences realized by virtue of an FDA. Both FDA and KWIC provide significant contributions to literary text linguistic analysis, notably in deciphering latent ideologies beyond the meaning propositions of plain language phrases.

The study establishes that modal verbs in language have ideological meaning. This is consistent with Fowler's [29] notion that language and ideology have a reciprocal relationship, because each linguistic expression (i.e., word, phrase, and sentence) can express the user's individual ideology. Ideology is usually present in language, and the use of specific verbal expressions over others has an ideological basis within textual analysis. That is, it is generated in this specific fashion and with this unique linguistic expression to communicate the speaker/specific writer's ideological connotations. As a result, every single word might reflect the user's philosophy. It is not simply content words that express and preserve ideas in conversation in the context of this study.

The analysis further clarified that function words, on the other hand, play an important role in communicating and maintaining ideals. Function words lose their common semantic meaning in certain discourse circumstances in order to express additional ideological goals. Modality, either classified as obligation or categorized as truth, is also used to portray deceptive ideology. The obligation and truth modal verbs are also employed to convey necessity and certainty. In the oppressive discourse, all of these methods are more representative. This is consistent with prior research [5], [11], and [41], which emphasize the ideological significance of modality.

The current linguistic investigation also reveals that modality in Bond's Lear is used to deliver persuasive ideas (must, will). The modals obligation and truth are used to convey requirement and certainty. These modal verbs are used to present a convincing ideology that is founded on facts and previous experiences. This aligns with the argument of Sornig [42], who postulates that within ideological discourse, the persuasive purposes beyond discourse can be deciphered by a variety of linguistic tools, including semantic, pragmatic and grammatical devices. This, for him, emphasizes the fact that the different levels of linguistic analysis can analytically be integrated towards the realization of the intended meaning of the speaker/writer. Thus, the linguistic investigation of texts can be conducted at the syntactic, semantic, pragmatic and/or grammatical levels.

\section{CONCLUSION}

The current study used a computer-assisted text analysis to decipher the ideological importance of modal verbs (will, must, and mustn't) in Edward Bond's Lear dialogue. The study employed two analytical approaches: first, critical discourse analysis, as described by Fairclough's model of analyzing discourse in terms of its grammatical features; and second, computer-aided text analysis, which is analytically enabled by CATA's three variables: frequency distribution analysis (FDA), key word in context (KWIC), and content analysis (CA). The three techniques are analyzed to see how much each modality contributes to the communication of specific beliefs in the selected text, ranging from persuasion to manipulation. The use of modality for ideological reasons was demonstrated in the analysis of the chosen play. The analysis also clarified that the various ideological meanings in discourse can be exposed by the skillful usage of modal verbs. These modal verbs in particular contexts cease to convey their ordinary semantic purpose of, for example, agency, certitude, obligation, etc., and channel further and new meanings either at the character-to-character or author-to-reader levels of communication. The analysis further revealed that modal verbs in light of this article are utilized used to bring about two types of ideology: manipulative and persuasive; the former always serves the interests of the speakers and/or writers, whilst the latter frequently functions to address the interests of all participants involved in any communicative acts.

Finally, this study suggests that other CATA variables, such as LWIC (Linguistic Inquiry and Word Count) and DICTION (software package with 31 predefined Dictionaries), be applied to the textual, pragmatic, stylistic and thematic analysis of other types of function words, such as the ideological analysis of prepositions, conjunctions, and demonstratives. This could lead to different and/or comparable conclusions than those presented in this research. The report also suggests that CATA software be used in the field of EFL teaching and learning, notably in literature courses. This may result in improved student learning outcomes as well as the development of innovative teaching approaches on the side of teachers.

\section{ACKNOWLEDGMENT}

I take this opportunity to thank Prince Sattam Bin Abdulaziz University in Saudi Arabia alongside its Scientific Deanship, for all technical support it has unstintingly provided towards the fulfillment of the current research project.

REFERENCES

[1] J. Reddington, F. Murtagh, and C. Douglas, "Computational properties of fiction writing and collaborative work," International Symposium on Intelligent Data Analysis, pp. 1-13, 2013.

[2] A. F. Khafaga, and I. Shaalan, "Using concordance to decode the ideological weight of lexis in learning narrative literature: A computational approach," International Journal of Advanced Computer Science and Applications, vol. 11, no. 4, pp. 246-252, 2020.

[3] K. Beatty, Teaching and researching computer-assisted language learning. Harlow: Longman Pearson, 2010.

[4] A. Thabet, "Applied computational linguistics: An approach to analysis and evaluation of EFL materials," Damietta Faculty of Education Journal, vol. 1, no. 13, pp. 7-39, 1990.

[5] A. F. Khafaga, and I. Shaalan, "Pronouns and modality as ideology carriers in George Orwell"'s Animal Farm: A computer-aided critical discourse analysis," TESOL International Journal, vol. 16, no. 4.2, pp. 78-102, 2021.

[6] M. Eltahir, S. Al-Qatawneh, and S. Alsalhi, "E-Textbooks and their application levels, from the perspective of faculty members at Ajman University, U.A.E," International Journal of Emerging Technologies in Learning, vol. 14, no. 13, pp. 88-104, 2019.

[7] G. Stockwell, Computer-assisted language learning: Diversity in research and practice. Cambridge: Cambridge University Press, 2018.

[8] J. Sinclair, Corpus, concordance collocation. Oxford: Oxford University Press, 1991. 
[9] A. F. Khafaga, Strategies of political persuasion in literary genres: A computational approach to critical discourse analysis. Germany: LAMBERT Publication, 2017.

[10] D. Wiechmann, and S. Fuhs, "Concordancing software," Corpus Linguistics and Linguistic Theory, vol. 2, no. 2, pp. 107-127, 2006.

[11] N. Fairclough, Language and power. London and New York: Longman, 1989.

[12] E. Bond, Lear, In plays two. London: Eyre Methuen, 1978.

[13] C. Pim, "Emerging technologies, emerging minds: Digital innovations within the primary sector," in G. Motteram (Ed.), Innovations in learning technologies for English language teaching, London: British Council, 2013, pp. 17-42.

[14] J. Jarvis, and L. Pastuszka, "Electronic literacy reading skills and the challenges for English for academic purposes," CALL-EJ Online, vol. 10, no. 1, 2008.

[15] S. Pinner, "Teachers' attitudes to and motivations for using CALL in and around the language classroom," Procedia-Social and Behavioral Sciences, 34, pp. 188-192, 2012.

[16] R. Fowler, and G. Kress, "Critical linguistics," in Fowler, R., Hodge, R., Kress, G., and T. Trew, T., (Eds). Language and control. London: Routledge and Kegan Paul, 1979, pp. 185-213.

[17] T. A. van Dijk, "Ideological discourse analysis," in Ventola, E., and Solin, A. (Eds.), Interdisciplinary approaches to discourse analysis. New Courant, pp. 1995, 135-116.

[18] Q. Ma, "From monitoring users to controlling user actions: A new perspective on the user-centred approach to CALL," Computer Assisted Language Learning, vol. 20, no. 4, pp. 297-321, 2007.

[19] S. Hockey, A guide to computer applications in the humanities. London: The Johns Hopkins University Press, 1980.

[20] G. Kennedy, An introduction to corpus linguistics. London \& New York: Longman, 1998.

[21] A. Barger, and K. Byrd, "Motivation and computer-based instructional design," Journal of Cross-Disciplinary Perspectives in Education, vol. 4, no. 1, pp. 1-9, 2011

[22] Y. H. Chen, "Computer mediated communication: The use of CMC to develop EFL learners' communicative competence," Asian EFL Journal, vol. 7, no. 1, pp. 167-182, 2005.

[23] G. Stockwell, "Computer-assisted language learning: Diversity in research and practice. Cambridge: Cambridge University Press, 2018.

[24] K. Romeo, "A web-based listening methodology for studying relative clause acquisition," Computer Assisted Language Learning, vol. 21, no. 1, pp. 51-66, 2008.

[25] R. Dzekoe, "Computer-based multimodal composing activities, selfrevision, and L2 acquisition through writing," Language Learning \& Technology, vol. 21, no. 2, pp.73-95, 2017.

[26] J. Flowerdew, "Concordancing as a tool in course design," System, vol. 21, no. 2, pp. 231-244, 1993.

[27] D. Krieger, "Corpus linguistics: What it is and how it can be applied to teaching," The Internet TESL Journal, vol. IX, no. 3, pp. 123-141, 2003.
[28] T. A. van Dijk, "Discourse, knowledge and ideology: Reformulating old questions and proposing some new solutions, in Martin, P., Aertselaer, J. N. and van Dijk, T. A., (Eds.), Communicating ideologies: Multidisciplinary perspectives on language, discourse, and social practice. New York \& Oxford: Peter Lang, 2004, pp. 5-38.

[29] R. Fowler, "On critical linguistics," in Coulthard, C., and Coulthard, M., (Eds.), Texts and practices: Readings in critical discourse analysis. London \& New York: Routledge, 1996, pp. 15-31.

[30] T. A. van Dijk, "Ideology and discourse analysis," Journal of Political Ideologies, vol. 11, no. 2, pp. 115-140, 2006.

[31] R. Fowler, Language in the news: Discourse and ideology in the press. London: Routledge, 1991.

[32] A. F. Khafaga, "Exploring ideologies of function words in George Orwell's Animal Farm," Pertanika Journal of Social Sciences and Humanities, vol. 29, no. 3, pp. $2089-211,2021$.

[33] F. Yavus, "The use of concordancing programs in ELT," ProcediaSocial and Behavioral Sciences, 116, pp. 2312-2315, 2014.

[34] A. Omar, A. F. Khafaga, and I. Shaalan, "The impact of translation software on improving the performance of translation majors," International Journal of Advanced Computer Science and Applications, vol. 11, no. 4, pp. 287-292, 2020.

[35] A. F. Khafaga, and A. Alghawli, "The impact of CALL software on the performance of EFL students on the Saudi university context," International Journal of Advanced Computer Science and Application, vol. 12, no. 7, pp. 304-312, 2021.

[36] A. F. Khafaga, and B. Aldossari, "The language of persuasion in courtroom discourse: A computer-aided text analysis," International Journal of Advanced Computer Science and Application, vol. 11, no. 7, pp. 332-340, 2021

[37] M. L. Heyden, J. Oehmichen, S. Nichting, and H. W. Volberda, H., "Board background heterogene-ity and exploration-exploitation: The role of the institutionally adopted board model," Global Strategy Journal, vol. 5, no. 2, pp. 154-176, 2015.

[38] A. F. Khafaga, "A computational approach to explore the extremist ideologies of Daesh discourse," International Journal of Advanced Computer Science and Applications, vol. 11, no. 8, pp. 193-199, 2020.

[39] W. Abraham, Modality in syntax, semantics and pragmatics. Cambridge: Cambridge University Press, 2020.

[40] A. Khafaga, "Linguistic manipulation of political myth in Margaret Atwood's The Handmaid's Tale," International Journal of English Linguistics, vol. 7, no. 3, 189-200, 2017.

[41] A. F. Khafaga, "Linguistic representation of power in Edward Bond's Lear: A lexico-pragmatic approach to critical discourse analysis," International Journal of English Linguistics, vol. 9, no. 6, 404-420, 2019.

[42] K. Sornig, "Some remarks on linguistic strategies of persuasion," in Wodak, R. (Ed.), Language, power and ideology: Studies in political discourse. John Benjamins Publishing Company,1989, pp. 95-113. 